\title{
Improvement of Voltage in Underground Mining Using PI Controller
}

\author{
Sukanth $\mathrm{T}^{1}$, and Prof. Singam Jayanthu ${ }^{2}$
}

\begin{abstract}
This paper presents the modeling and implementation of a three-phase DSTATCOM (Distribution Static Compensator) using Proportional Controller (PI) to improve power quality. It is used for harmonics elimination, load balancing and reactive power compensation at distorted PCC (Point of Common Coupling). The Power Quality management is the key issue in electrical power system and industries are facing these issues around the world. As the mining complexes are often remotely located, power is weak and unpredictable. The voltage at the equipment terminal determines the starting and running torques. Mining operation performance is strategically linked to the efficiency of electrical motors. In case of any typical underground mines starting a big motor such as is used on winders, crushers, haulers, pumps etc. particularly on weak systems, results in a large voltage drop, which significantly reduces the torque of the motor. Loads such as continuous miners mine hoists, mining shovels, crushers, etc. are in demand and also sensitive to voltage dips and fluctuations. Voltage dips or sags often causes equipment to trip, which in turn results in lengthy delays with resultant production and revenue losses. . In this paper, Proportional Controller (PI) is developed using MATLAB / SIMULINK for improving power supply to mining industry.
\end{abstract}

Keywords - Power Quality, Loads, Voltage,

\section{INTRODUCTION}

$\mathrm{F}$ EEDING safe and reliable power to mining complexes can be a challenging task. As per the Indian Electricity rules 1956 in explosive areas transformers, including booster transformers are not allowed inside a mine [2]. The difficult environment, the dynamic power loads, the cyclic and mobile operation and stringent safety requirements that characterize mining, all places unique demands on the mine power system. No other industry makes such extensive use of portable extensible equipment or has such complex grounding problems. Mine power systems can range from relatively simple installations for small surface mines to complex underground systems where the harsh environment of dust, humidity, and cramped spaces stretches the ingenuity and creativity of the engineer to provide reliable service. But today's mine power system is both complex and subject to numerous legal constraints, and it is no longer possible to treat it with the indifference of the past. The distance from the secondary power transformers to the working point inside a mine, are fairly long. This results in high voltage drops in the cables and poor voltages in the operating equipment. With all restrictions in high voltage capacitors, a substantial reactive power is generated through capacitor banks and supplied near the main transformer only [3]. However, this does not help in improving the voltage at the equipment terminals. The voltage at the equipment terminals determines the starting and running torques. Mining operation performance is strategically linked to the efficiency of the electrical motors that run countless operations across a plant. Loads such as continuous miners mine hoists, mining shovels, crushers, etc. are in demand and also sensitive to voltage dips and fluctuations. Mining complexes are often forced to operate in environments characterized by one or several of the following factors:

- Remote areas where power supplies are weak or inadequate

- Rough, inaccessible terrain, more or less unsuited for $\mathrm{OH}$ (Overhead) line construction

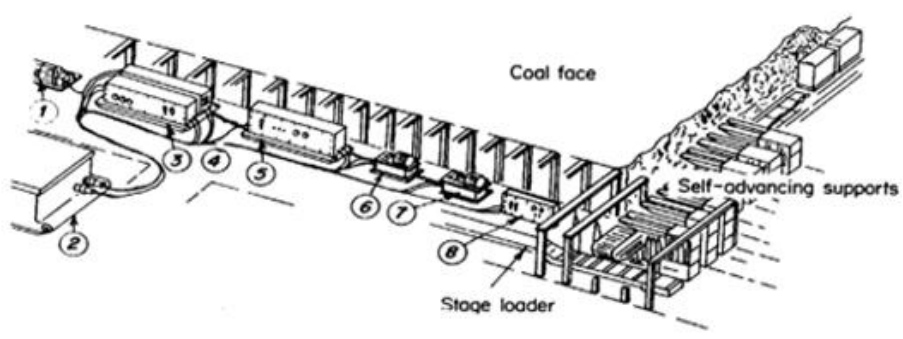

1. Motor, $125 \mathrm{hp} \quad 2.100 \mathrm{KVA}$ power center 3.125-hp stage loader starter4. Dual 125-hp face conveyer starter 5. Dual 75-hp pump and 230-hp shear star6 .Pump, 75-hp 7.Pump, 75-hp 8. Master control

Fig. 1 Shows Power-system segment with LongWall equipment

A typical Longwall mining system as shown in figure 1 consists of several electrically operated components, interfaced with the coal-haulage system for the time. The major components are the shearer unit, shearer controller, face conveyor unit, stage-loader unit, conveyor controller, hydraulic pump unit, pump controller, master controller and power center. Figure 2 shows shearer cutting Longwall face at GDK 10A underground mine and Figure 3 show substation in underground mine at ALP (Adriyala Longwall Project).

Sukanth. $\mathrm{T}^{1}$, Ph. D Research Scholar, Mining Engineering Department, National Institute of Technology, Rourkela, Odisha, India.

Dr. Singam Jayanthu ${ }^{2}$, Professor in Mining Engineering Department, National Institute of Technology, Rourkela, Odisha, India. 


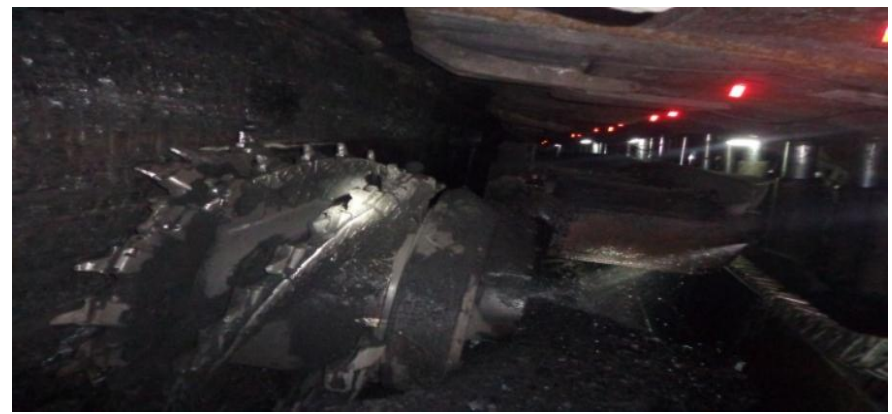

Fig. 2 Shearer cutting at Longwall face

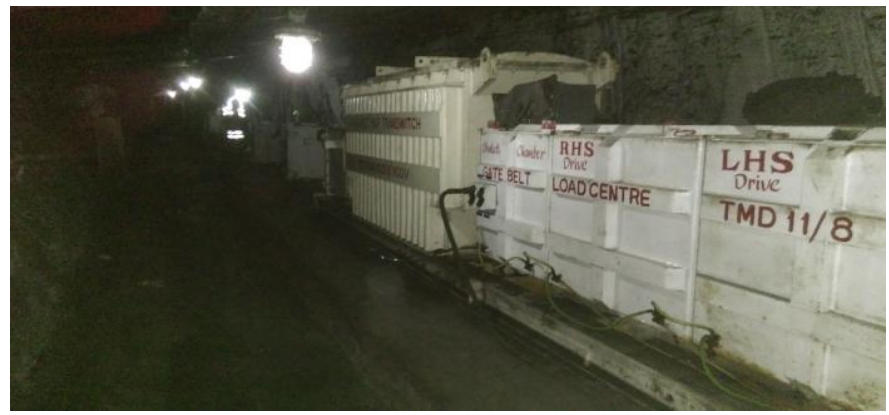

Fig. 3 Substation in underground mine at ALP

A traditional way to deal with shortcomings in power transmission as well as with poor or insufficient power quality is reinforcing the grid by building new lines, upgrading voltages to higher levels, or building local power plants to supply parts or the total of the load. Such measures are expensive and time-consuming, if, they are permitted. A cost effective way to introduce custom power devices, thereby utilizing existing facilities more efficiently. The proper use of this technology will benefit all the industrial, commercial and domestic customers with the following benefits;

- Continual Energy Efficiency

- Extended equipment life

- Reduced costs

- Reduced voltage fluctuations

\section{REVIEW OF LITERATURE}

The quality of power delivered to the end user is very important as the performance of the consumer's equipment is heavily dependent on it. But the power quality is affected by various factors like voltage and frequency variations, presence of harmonics, faults in the power network etc. [4]. Among them the voltage variations ( $\mathrm{sag}$ ) is one of the most frequently occurring problem. There are many methods to mitigate the voltage sag and among them the best way is to connect a CUSTOM POWER device at the point of interest. The wellknown devices like DSTATCOM, DVR, and UPQC are used for this purpose [5]. The world's earliest DVR's installation was done at Duke Power Company's $12.47 \mathrm{kV}$ substation in Anderson, South Carolina in 1996. After that immediately then $\mathrm{ABB}$, Siemens and other companies have also focused and worked hard for several years to achieve the design patterns and finally developed their own patterns of the products to ensure the quality of voltage-sensitive load.

\section{POWER QuALITY}

Power Quality is a term that refers to maintaining the near sinusoidal waveform of power distribution bus voltages and currents at rated magnitude and frequency [6]. Figure 4 shows sources of Power Quality problems.

\section{Key aspect of Power Quality \\ $>$ Power Factor \\ $>$ Harmonic \\ $>$ Disturbances \\ $>$ Distortion \\ $>$ Unbalance \\ $>$ Frequency}

\section{Major PQ Problems}

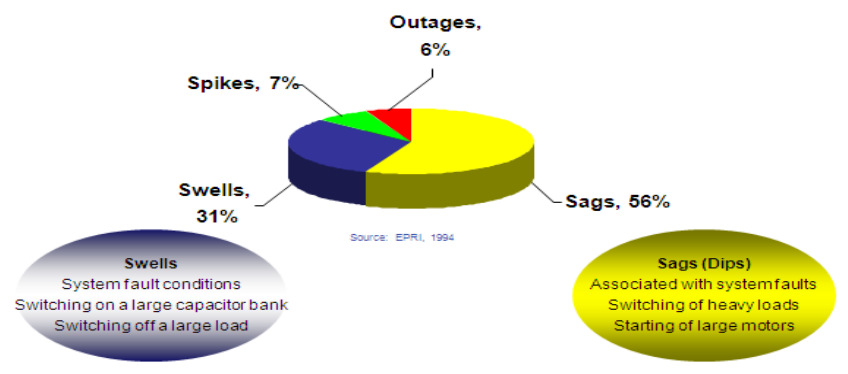

Fig 4. shows sources of Power Quality problems

\section{Custom Power DeVICES}

The voltage sag is a major problem that the power system network is facing now-a days. This is a severe problem and affects the functioning of the equipment. Therefore, this problem should be mitigated in order to maintain the efficiency of the power network. The use of custom power devices solves this problem. The concept of custom power was introduced by N.G. Hingorani in 1995 as an extension of the FACTS concept to distribution systems. The major objective is to improve power quality (PQ) and enhance reliability of power supply. The concept of FACTS was also proposed by Hingorani in 1988. The term 'custom power' describes the value-added power that electric utilities will offer their customers. The value addition involves the application of high power electronic controllers (similar to FACTS) to distribution systems, at the supply end of industrial, commercial customers and industrial parks. The provision of custom power devices (CPD) is complementary to the individual end-use equipment at low voltages (such as UPS (Uninterruptible Power Supply) or standby generators) [6].

The custom power devices that can be used in distribution systems [7] are:

1. Solid State (Thyristor Controlled) Transfer Switch (SSTS)

2. Solid State Circuit Breaker (SSCB)

3. Solid State Current Limiter (SSCL)

4. Distribution Static Synchronous Compensator

(DSTATCOM)

5. Dynamic Voltage Restorer (DVR) 
6. Active Filter (AF)

7. Static Var Compensator (SVC)

8. Thyristor Controlled Voltage Regulator (TCVR)

\section{A. DSTATCOM}

D-STATCOM is a shunt-connected CPD which can be used to regulate voltage variation resulting from the motor starting condition or in-rush current and to mitigate current harmonic distortions. A DSTATCOM is a controlled reactive source which includes a Voltage Source Converter (VSC) and a DC link capacitor connected in shunt, capable of generating and /or absorbing reactive power. It is analogous to an ideal synchronous machine, which generates a balanced set of three sinusoidal voltages at the fundamental frequency with controllable amplitude and phase angle. This ideal machine has no inertia, gives an instantaneous response, does not alter the system impedances, and can internally generate reactive (both capacitive and inductive reactive power). Fig.5 shows the basic structure of a DSTATCOM. If the output voltage of the VSC is equal to the AC terminal voltage; no reactive power is delivered to the system. If the output voltage is greater than the AC terminal voltage, the DSTATCOM is in the capacitive mode of operation and vice versa. The quantity of reactive power flow is proportional to the difference in the two voltages which is shown in Figure 5.

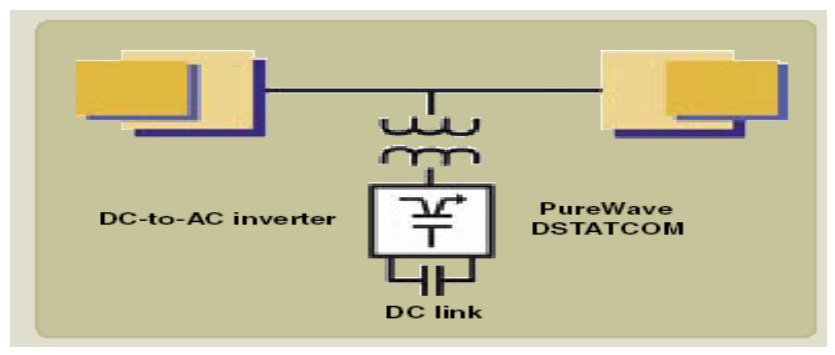

Fig 5. Shows sources basic block diagram of DSTATCOM

\section{PI CONTROLLER}

The aim of the control PI scheme is to maintain constant voltage magnitude at the point where a sensitive load is connected, under system disturbances. The control system only measures the r.m.s voltage at the load point, The VSC switching strategy is based on a sinusoidal Pulse Width Modulation (PWM) technique which offers simplicity and good response. Since custom power is a relatively low-power application, PWM methods offer a more flexible option than the Fundamental Frequency Switching (FFS) methods favoured in flexible alternating Current transmission systems (FACTS) applications. The controller input is an error signal obtained from the reference voltage and the value r.m.s of the terminal voltage measured. Such error is processed by a PI controller the output is the angle $\delta$, which is provided to the PWM signal generator. The PI controller process the error signal generates the required angle to drive the error to zero, i.e., the load r.m.s voltage is brought back to the reference voltage which is shown in Figure 5.

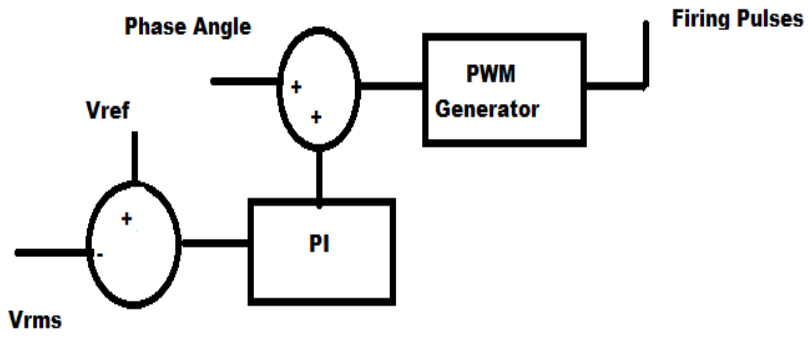

Fig. 6 Block diagram of PI controller

\section{RESULTS}

Electrical data has been collected from GDK-10A underground mine and based on the data collected, power system model has been developed in MATLAB / SIMULINK. The simulations are performed for the cases: (i) without compensation and (ii) with compensation. The system performance is analyzed. These cases are summarized below:

\section{Case (1): Without compensation}

Model has been simulated for one second and load 1 (375 $\mathrm{KW}$ ) is switched on between 0.3 to $0.5 \mathrm{sec}$ and load 2 $(250 \mathrm{KW})$ is switched on between 0.6 to $0.8 \mathrm{sec}$. After switching $\mathrm{ON}$ the load, the voltage was falling down and decreased to a certain level. Similarly ALP loads are taken as $400 \mathrm{KW}, 855 \mathrm{KW} \& 855 \mathrm{KW}$. Simulation results are shown in Figures [7-10]. The Total Harmonic Distortion (THD) without compensation observed is $28 \%$ at $50 \mathrm{~Hz}$ fundamental frequency which is high.

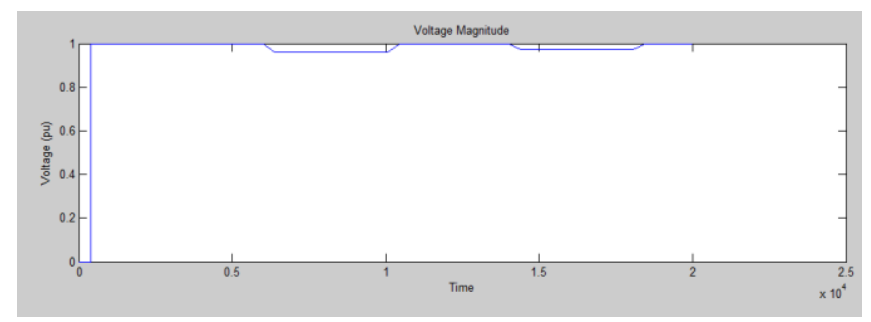

Fig 7. Load Voltage Magnitude (GDK-10A)

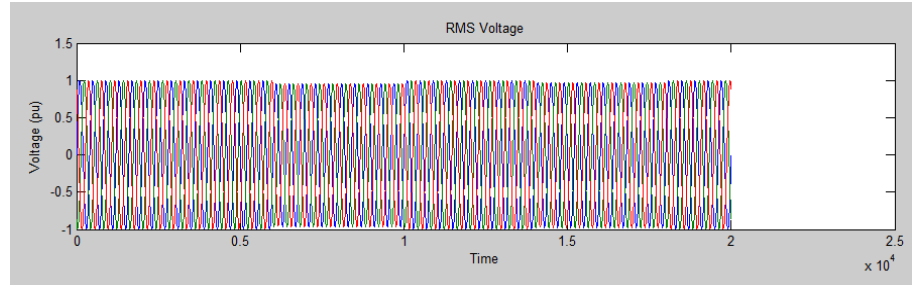

Fig 8. Load Voltage (GDK-10A)

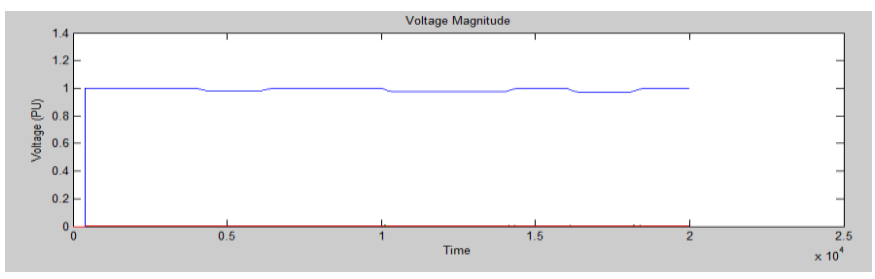

Fig 9. Load Voltage Magnitude (ALP) 


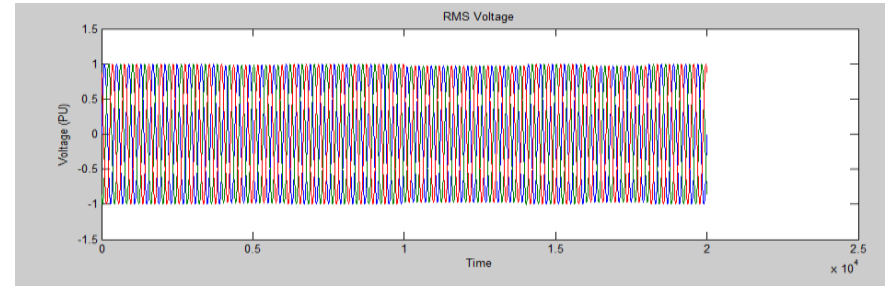

Fig 10. Load Voltage (ALP)

Case (2): With compensation

After PI controller is added the results obtained from the simulation shows that the compensation offered by PI controller is much better than without compensation. The THD is reduced to $15.12 \%$ and result is shown in Figures [11- 14]. A comparison of parameters is tabulated in Table 1.

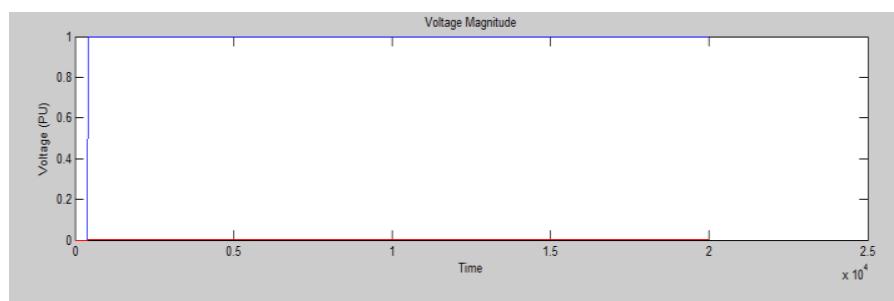

Fig 11. Load Voltage Magnitude (GDK-10A)

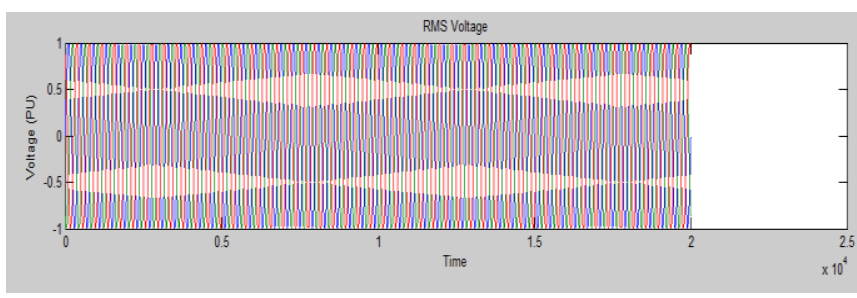

Fig 12. Load Voltage (GDK-10A)

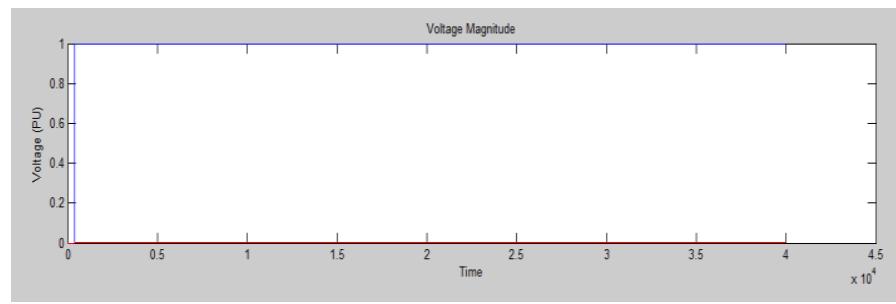

Fig 13. Load Voltage Magnitude (ALP)

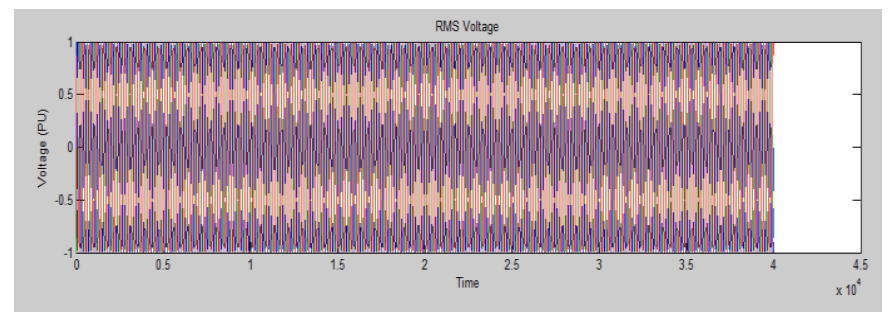

Fig 14. Load Voltage (ALP)

TABLE I

COMPARISON OF PARAMETERS

\begin{tabular}{|c|c|c|}
\hline Parameters & Without controller & With PI controller \\
\hline $\begin{array}{c}\text { Reactive Power } \\
\text { compensation }\end{array}$ & Unsatisfactory & Satisfactory \\
\hline $\begin{array}{c}\text { Performance } \\
\text { under } \\
\text { balanced loads }\end{array}$ & $\begin{array}{c}\text { Contains desired } \\
\text { harmonics }\end{array}$ & $\begin{array}{c}\text { Reduced } \\
\text { Harmonics }\end{array}$ \\
\hline THD & $28 \%$ & $15.12 \%$ \\
\hline
\end{tabular}

\section{CONCLUSION}

The demand for electric power is increasing at an exponential rate and at the same time the quality of power delivered became the most prominent issue in the power sector. Thus, to maintain the quality of power the problems affecting the Power Quality should be treated efficiently. Among the different power quality problems, voltage sag is one of the major one affecting the performance of Longwall Mining. Therefore, simulation of electrical layout of typical mines and associated studies mentioned above will be highly beneficial to the mining industry by improving power factor, voltage sag and reduction of harmonics PI controller is discussed to decrease voltage sag problem in Mining Industry. After the application of PI controller THD is reduced to 15.12 $\%$.

\section{REFERENCES}

[1] Bollen, Math H J. "Understanding power quality problems". Vol. 3. New York: IEEE press, 2000L. C. Kaku , "A study of Indian electricity rules", 1956

[2] Lloyd, A. M. "Mine Power System" Information circular: 9258 Library of Congress Docs. no.: 128.27:9258, 1991.

[3] Arya, Aadesh Kumar, Amit Kumar Manocha, J. S. Arya, and Manoj Kumar, "Compensation scheme for power quality improvement in present power system", Recent Advances in Engineering and Computational Sciences, 2014, pp. 1-6.

[4] Natan, G., Lennart, M., and Payer, Christian. "Dynamic Var compensation of mine hoists for improvement of power quality and increase of productivity at LKAB Sweden". 20th International Conference and Exhibition on Electricity Distribution-Part 1, CIRED, pp. 1-4. IET, 2009.

[5] Ghosh, Arindam, and Gerard, F. "Power quality enhancement using custom power devices ". Kluwer academic publishers, 2002.

[6] Farhoodnea, M., Mohamed, A. and Shareef, H. "A comparative study on the performance of Custom Power devices for Power Quality improvement". International Conference in Innovative Smart Grid Technologies-Asia, pp. 153-157. IEEE, 2014. http://dx.doi.org/10.1109/isgt-asia.2014.6873781

[7] Sukanth, T., Srinivas, D., Zefree, Lazarus, Pritam Satsangi, K., "Comparative study of different control strategies for DSTATCOM", International Journal of Advanced Research in Electrical, Electronics and Instrumentation Engineering, 2012, Vol. 1, Issue 5.

[8] Luiz, Amavel. , Alex-Sander, and Braz de Jesus Cardoso Filho. "Improving power quality in mining industries with a three-level active front end." In Industry Applications Society Annual Meeting, pp. 1-9. IEEE, 2015.

[9] Natan, G., Lennart, M., and Payer, Christian. "Dynamic Var compensation of mine hoists for improvement of power quality and increase of productivity at LKAB Sweden". 20th International Conference and Exhibition on Electricity Distribution-Part 1, CIRED, pp. 1-4. IET, 2009.

[10] Singh, Bhim. , Dube, Sunil Kumar., and Arya, Sabha, Raj. "An improved control algorithm of DSTATCOM for power quality improvement." International Journal of Electrical Power \& Energy Systems, pp. 493-504. IJEPES, 2014.

[11] Singam, Jayanthu. A Report on "Strata Monitoring in Longwall Panel no.3d1 \& 3d2 of GDK.10A, APA, SCCL ", NIT, Rourkela, 2013.

[12] Sridevi, J., Amaranth. , and Govinda Rao, G. "Zonal Power Quality improvement using Static Var Compensator for an Indian Utility System" International Journal of Engineering Research, pp.1320-1325, IJERA, 2012.

[13] Vivek, M. "Power quality improvement techniques in hybrid systems-A review ". International Journal of Advanced Technology \& Engineering Research, pp.56-59. IJATER, 2014 